\title{
What industry requires from the application of research from equine science \\ JR Winfield \\ ${ }^{1}$ British Horse Society, Warwickshire, United Kingdom, ${ }^{2}$ Hartpury College, Gloucester, United Kingdom \\ Email: jowinfield@hotmail.com
}

The equestrian industry contributes approximately $£ 3.4$ billion to the UK according to the Henley Report (2004), it is responsible for 5 million consumers (11\% of the population) declaring having an active interest in some form of the industry. This is also made up of 50,000 people directly and 150,000 - 250,000 indirectly employed in the equestrian industry. It is frequently subjected to criticism for relying on traditional approaches to solving management problems. The transfer of knowledge between equestrian generations often relies on authoritative transfer of knowledge, rather than a critical empirical approach. However, alongside this over-reliance on authority equestrian experience has been developed from observation and questioning of observed behaviour both directly with the horse and within its environment. In fact for the equestrian coach these skills in observation and reflection are an integral part of coaching practice. The wealth of knowledge that resides within the equestrian industry professional therefore should not be underestimated.

A lot of the knowledge of an equestrian professional is tacit, and therefore difficult to articulate. This is compounded by belonging to a community of speech practice that has a detailed and complex 'argot'. The potential for miscommunication with individuals outside this community is therefore great and can lead to assumptions that the equestrian professional has little knowledge to offer outside their direct environment. The integration of UKCC qualifications and the recognition that a 'riding instructor' may also be a skilled coach, communicator and professional has led to greater reflection within the equestrian industry. The increased focus on how the equestrian industry is perceived externally and the recognition that external benchmarking can be utilised to increase its status has opened the path for interdisciplinary communication and study that may not have been previously available.

Much of the research that has been undertaken in equestrian science to date has been establishing fundamental knowledge, often about physiological or performance based dilemmas about which a lot of comparative information is known. However when we consider more complex questions, especially those incorporating dyad relationships, e.g. horse and rider, there is very little, or in some cases no, comparative information to draw on. In these cases if research does not utilise the tacit knowledge within the equestrian industry researchers have to spend a great deal of time and effort establishing the reliability of information that an equestrian professional would consider so basic as to not be worthy of mention. The presentation of this information as new research can do untold damage in the name of equestrian research as professionals often regard it as simplistic, condescending and ultimately 'a waste of time'. Whilst this research can be valuable it must be communicated at a level appropriate to its impact within the industry, and to its audience.

Research should therefore be applied to the industry, and communication of this fundamental knowledge should be kept to those that it would benefit. There is a huge opportunity for collaboration and two way learning, to integrate best practice and work together to solve many of the challenges that face the equestrian industry. In this way research would increase its status, its funding and also its value and application to both riders and lay professionals who can have high kudos within their chosen field. 